\title{
Metamorfosis: La animalidad y el mito en La Metamorfosis de Kafka y Axolotl de Cortázar.
}

\author{
Metamorphosis: Animality and Myth \\ in Metamorphosis of Kafka and Axolotl of Cortázar.
}

\begin{abstract}
Resumen
El presente artículo propone una lectura de la animalidad, principalmente de la metamorfosis, por medio de dos relatos de dos grandes escritores de la literatura: Axolotl, de Julio Cortázar, y La Metamorfosis, de Franz Kafka. A través de estos textos, se plantea un análisis con respecto a lo que representa una transformación y el mito tras la metamorfosis como tal.
\end{abstract}

Palabras claves

Metamorfosis. Axolotl, animalismo, mito.

\begin{abstract}
The present article proposes an analysis of animality, especially the metamorphosis through two classical stories: Axolotl, by Julio Cortázar and Metamorphosis, by Franz Kafka. Using both stories, this piece of work pretends to show what a transformation and a myth can represent through the metamorphosis itself.

Keywords Metamorphosis, Axolotl, animality, myth.
\end{abstract}

Sin duda, es muy amplio y extenso el campo cuando se trata de mitos. El mito, a diferencia de la creencia popular, no corresponde al opuesto de realidad, sino al conocimiento del origen de algo. En palabras de Mircea Eliade, "conocer 
los mitos es aprender el secreto del origen de las cosas. En otros términos: se aprende no sólo cómo las cosas han llegado a la existencia, sino también dónde encontrarlas y cómo hacerlas reaparecer cuando desaparecen" (21).

Esto puede verse reflejado en el complejo campo de la literatura:

Donde existe una serie de mitos que van unidos al nombre de un personaje prototípico sino que son más bien temas míticos que responden a una serie de características constitutivas que los escritores actualizan en relatos pertinentes a ciertos géneros, como por ejemplo la literatura fantástica, ciencia ficción, la novela lírica, etc. (Juan Herrero Cecilia 67)

Prácticamente desde el Romanticismo, hemos podido apreciar cómo los estudios acerca de los mitos se basan principalmente en la comparación y es en este punto donde se logra una unión de mutuo acuerdo entre el estructuralismo y psicoanálisis, este último bajo una perspectiva en su mayoría Freudiana acerca de los mitos.

No obstante, también encontramos el enfoque de Jung, quien asevera que todo símbolo se convierte en figura mítica luego de formar parte de una elaboración colectiva, histórica y concreta, específicamente acuñada en las leyendas y relatos míticos.

Sucede en estos relatos míticos algo similar al mundo fantástico, que comienza con la presentación de una realidad cotidiana que en el intervalo se ve forzada a un cambio, debido a veces a una fuerza sobrenatural inexplicable, en un comienzo, que por lo general en el transcurso del relato se logra comprender, de forma natural y/o sobrenatural.

Los esquemas míticos, como menciona Herrero Cecilia, pueden aparecer de forma explícita, "ya sea por el nombre de los personajes como por el tipo de historia narrada" (67). 
CATEDRAL Tomada: Revista de crítica literaria latinoamericana / Journal of Latin American Literary Criticism Metamorfosis: La animalidad y el mito en La Metamorfosis de Kafka y Axolotl de Cortázar.

Esto se debió, quizás en parte, a que la mayoría de los mitos consiste en argumentos simples que explican desde tiempos remotos los patrones del comportamiento dirigidos a conductas tan primitivas como la búsqueda de alimento y la sexualidad; sin embargo, y para formar parte de la literatura, debieron añadirle peculiaridad o algún elemento singular que acompañara estos hechos. El campo de estos resulta muy extenso, por lo que nos enfocaremos exclusivamente en la metamorfosis.

La metamorfosis es entendida como un equivalente a transformación, un proceso por el cual un objeto o entidad sufre un cambio. Este transcurso suele asociarse también a ciertos animales que experimentan estos cambios biológicos, generalmente durante su desarrollo para así adoptar una forma o estilo definitivo que complementa sus funciones de vida.

La metamorfosis entonces propone un cambio, una transformación y no necesariamente está ligada a un proceso que sufre un animal, sin embargo en este caso, nos encauzaremos en la metamorfosis desde la animalidad, es decir, aquellas características propias de los animales y su opuesto al humano en diversos aspectos.

La animalidad ha sido objeto de estudio tanto en la filosofía como en la literatura, donde en ambos campos ha sido abordada en profundidad. El tema de la animalidad del hombre o de las relaciones del hombre con el animal siempre han estado presentes de una forma u otra en todas las culturas: "El hombre ha alcanzado ya su telos histórico y, para una humanidad que ha vuelto a ser animal, no queda otra cosa que la despolitización de las sociedades humanas" (Agamben 418).

Bajo la disciplina filosófica, el animalismo ha sido tratado como un tema antropológico. El humano resulta ser el producto final de una diferenciación entre él y el lado bestial (que generaría, claro, el animal de por sí), oponiéndose, de esta manera, la idea de humanidad. 
Para la literatura, sin embargo, la animalidad no tiene sólo esta función y distinción, sino que también, este tema resulta de real importancia al momento de cuestionar la dualidad animalidad- humanidad.

A través del análisis de dos obras literarias veremos cómo se reflexiona, con base en esta relación establecida, la oposición que producen en un comienzo ambos conceptos y el replanteamiento que surge al notar en el uno un complemento del otro.

Una de las obras es Axolotl, de Julio Cortázar, donde el narrador desde el comienzo retrata su fascinación por los axolotls. En este relato, se entrelaza la animalidad, o sea, la condición animal y la metamorfosis que unen al axolotl con el humano.

Al inicio, ya podemos apreciar la intención del narrador, un sujeto que inmediatamente presenta dos identidades: el hombre y el axolotl. Es precisamente en esta primera parte cuando el narrador declara que antes no era un axolotl y ahora sí, despejando, de esta forma, toda posibilidad de duda al respecto.

El personaje decide establecer un primer contacto con estos animales en el momento que resuelve ir a visitar el acuario de Jardín des Plantes, donde, observando los peces, se encuentra inesperadamente con los axolotl.

Todo esto acontece en París, y los animales de los que habla y visita habitan el zoológico, por lo que, por su forma de expresar las ideas y su entorno europeo, se logra apreciar a un hombre moderno, solitario, tal vez incomprendido y atrapado por esta realidad, a la cual no quiere pertenecer, lo que nos sugiere que pueda estar en búsqueda, quizás, de una salida de este fracaso social.

En palabras de Herrero-Cecilia (63), en cuanto a los esquemas míticos, muchos de ellos pueden aparecer en los textos literarios de una manera explícita, ya sea por el nombre del personaje como por el tipo de historia narrada $y$, sin duda, este relato tiene algo de ambos.

El axolotl, o ajolote, es un anfibio proveniente de México. Su único hábitat natural son los lagos, canales o cuevas próximos a la Ciudad de México. 
Considerando esto, es imposible no detenerse en el sugerente título que lleva esta historia, que es precisamente el nombre de este anfibio que lleva la letra " $x$ ", la cual nos remite aún de forma más profunda a México y su pasado ancestral. Las descripciones que hace el protagonista reafirman una fuerte conexión hacia el mundo aborigen mexicano. La piedra rosa de la cabeza (Cortázar 8) y la total certeza que el protagonista tiene respecto al sufrimiento de estas criaturas: "No era posible que una expresión tan terrible que alcanzaba a vencer la inexpresividad forzada de sus rostros de piedra, no portara un mensaje de dolor, la prueba de esa condena externa, de ese infierno líquido que padecían " (Cortázar $6)$.

Así también pareciera entenderlo el narrador, quien en reiteradas ocasiones hace alusión a los axolotl y su origen: "Que eran mexicanos lo sabía ya por ellos mismos" (Cortázar 2), “detrás de esas caras aztecas” (6), remontándonos así a mundos antiguos que irrumpen la realidad, la modernidad, el contraste entre el mundo azteca y la actualidad parisina.

El mundo azteca, antiguo, al igual que los axolotl, son entes olvidados, residuos de esa época olvidada y el opuesto radical del protagonista, que habita en un contexto totalmente distinto.

Pertinente resulta entonces recalcar en este punto el nexo entre la identidad latinoamericana y el mundo europeo. Podemos apreciar cómo lo originario, vale decir, la cultura azteca, acaba como algo olvidado, un adorno en forma de acuario en la sociedad moderna de París. Por otro lado, está también la contraparte donde podemos apreciar cómo, por medio de la literatura, es decir, los relatos del protagonista, hay un empoderamiento de Europa, pese a estar éste inmerso en un acuario, aún persiste una identidad propia.

Frases como "La inexpresividad forzada de sus rostros de piedra", producen una conexión entre el lector y este mundo olvidado y añoso. De esta forma, el lector se transporta a las ruinas y todos aquellos vestigios de roca, las constantes asociaciones al oro que se encuentran en el relato, lo que nos indica también una cercanía al antepasado místico. Cabe mencionar que en la medicina 
tradicional mexicana se pueden encontrar jarabes de axolotl para tratar enfermedades respiratorias, lo que hace a este animal un ser ancestral, cura, se relaciona con la medicina, con la recomposición. El hecho de ser anfibio enlaza la evolución de pez y hombre.

Lo curioso es que finalmente lo que hace el protagonista de Cortázar es justo al revés, él vuelve a sus orígenes, termina finalmente convertido en un axolotl y lo hace en Europa. Que la historia se desarrolle en París y el axolotl sea una criatura mexicana no es casual. Nos encontramos frente a un hombre moderno, solo, ensimismado en su soledad, que parece querer escapar de la ciudad y encuentra paz en la contemplación de los axolotl en el acuario, algo que sugiere a veces la idea del mito del eterno retorno, el regreso al origen.

Por otro lado, en el cuento La Metamorfosis, de Franz Kafka, vemos una metamorfosis bastante más gráfica, comenzando por el nombre, el cual ya nos indica lo que terminará sucediendo. A diferencia de Axolotl, el relato de Kafka comienza con la metamorfosis consumada, en que el protagonista, Gregorio Samsa, despierta en su cama convertido en un horrible insecto. Su conciencia humana va, poco a poco, perdiendo fuerza y acaba en una conciencia animal.

De similar forma al protagonista de Axolotl, Gregorio es un hombre solitario, a pesar de vivir con su familia y mantenerla económicamente, es un vendedor viajero, lo cual nos indica inmediatamente que nos encontramos ante un hombre maltratado, un proveedor cansado cuyo cuerpo debe soportar probablemente pensiones nefastas y malas comidas.

La principal metamorfosis es la interior, resultando hasta cierto punto irrelevante su aspecto físico. Al inicio del relato Gregorio piensa, es en su interior aún un humano, sin embargo, al transcurrir la historia, termina siendo un ser elemental.

En un comienzo Gregorio puede hablar, hay una comunicación entre él y su familia; sin embargo, cada vez este es más animal y al otro lado de la puerta es reconocida su transformación cuando el apoderado, personaje que irrumpe en su hogar, reconoce en él una "voz de animal". No lo han visto y sin embargo ya 
CATEDRAL Tomada: Revista de crítica literaria latinoamericana / Journal of Latin American Literary Criticism Metamorfosis: La animalidad y el mito en La Metamorfosis de Kafka y Axolotl de Cortázar.

reconocen que no es un humano. La misma propiedad que lo delata le es arrebatada en el transcurso del relato, al terminar formando parte de los animales no parlantes. Así como en Cortázar, aquí hay una definición ajena, en este caso humana de lo que es o no animal. Son los otros que dicen que ambos son animales, cuando tienen conciencia de que no lo son, en realidad

En Axolotl, también vemos una metamorfosis interior. El hombre, narrador, después de ir al acuario, se transforma en axolotl. En sus palabras se logra apreciar la metamorfosis que traspasa el espacio público, cuando este comenta que descubre el sentido de horror de una persona que está sepultada y de pronto despierta (Cortázar 7). Se podría decir entonces, que ambos protagonistas estaban "sepultados" en sus cuerpos humanos, solitarios y cansados, y de pronto despiertan de esta pesadilla con la metamorfosis ya consumada.

Al mismo tiempo, el axolotl transforma al protagonista. Están conectados, hombre y axolotl tienen la facultad de observar dentro y fuera del acuario. Todo el relato trata las percepciones de un individuo inmerso en una cultura a la cual no quiere pertenecer y se descubre a sí mismo a través del axolotl, dejando parte de él en el animal.

Y sin duda, la conexión surge desde el primer momento, desde la primera visita del acuario del Jardín des Plantes, el narrador se entrelaza con este animal, acentuando la intercomunicación y a su vez enfatiza también la intensa afinidad y atracción que siente por los axolotl.

"Ya era un axolotl y sabía ahora instantáneamente que ninguna comprensión era posible" (Cortázar 7). Con esta declaración, no queda claro en qué tiempo ocurre este hecho, ni desde cuándo, él sabe que ninguna comprensión era posible. No solo la temporalidad es ambigua, sino también el momento de la transformación del protagonista.

En un comienzo y cuando estos animales captan su atención, comienza a interesarse por obtener más información sobre ellos, pero conocimiento desde su percepción, a través de sus sentidos, rechazando todo material académico y textos 
especializados al respecto, estableciendo de esta manera, semejanzas entre el animal y el hombre. Demostrando de esta manera un retorno a lo primitivo.

Por su parte, en la Metamorfosis de Kafka, vemos a Gregorio transformado en este horrible insecto desde el primer momento, pero, aunque sea/esté insecto, él conserva su tamaño natural de humano.

Gregorio en un comienzo intenta erguirse, sin embargo le resulta imposible y cada día se va convenciendo más de que es un bicho. Toda su percepción y temporalidad se va alterando y termina siendo la criatura elemental que desde un comienzo nos es presentada en apariencia física.

Gregorio, encerrado en su habitación, no logra distinguir al médico y al cerrajero, y no se siente incluido en el círculo humano, ni siquiera comparte las cenas con su familia, sus padres y hermana, esta última responsable de sus comidas. Ella, le ofrece en un momento los restos de alimento, Gregorio los acepta y termina comiendo queso añejo y todos aquellos productos que en su condición de humano había rechazado días previos, catalogándolos de “incomibles” (Kafka 20).

Tarda el protagonista en concluir que finalmente es un insecto:

Allí permaneció durante toda la noche, que pasó, en parte, inmerso en un semisueño, del que una y otra vez lo despertaba el hambre con un sobresalto, y, en parte, entre preocupaciones y confusas esperanzas, que lo llevaban a la consecuencia de que, de momento, debía comportarse con calma $\mathrm{y}$, con la ayuda de una gran paciencia y de una gran consideración por parte de su familia, tendría que hacer soportables las molestias que Gregorio, en su estado actual, no podía evitar producirles. (Kafka 19) 
CATEDRAL Tomada: Revista de crítica literaria latinoamericana / Journal of Latin American Literary Criticism Metamorfosis: La animalidad y el mito en La Metamorfosis de Kafka y Axolotl de Cortázar.

Gregorio pasa de ser el integrante más importante de su núcleo, el proveedor, a un ser totalmente dependiente, incapaz de erguirse y obtener su propio alimento.

La mutua unión y discrepancia se aprecia de igual forma en Axolotl, en el momento que el narrador se conecta con el animal, descubre que el axolotl tiene alma y al igual que él, reclama comunicación, ambos finalmente quedan atrapados, ya que son seres incompatibles física y mentalmente.

A pesar de esto, el protagonista asevera: "Desde un primer momento comprendí que estábamos vinculados, que algo infinitamente perdido y distante seguía sin embargo uniéndonos" (Cortázar 2). Esto hace que finalmente, entonces, el cristal del acuario sea la barrera principal que impide que el hombre se encuentre con su verdadero yo y no así la apariencia o aspecto físico. Debido a esto, la fusión del sujeto con su sujeto estudiado llega por medio de la contemplación. Así como ocurre también con Gregorio Samsa, el narrador en este caso, es definitivamente el animal, y, si hasta el final del relato, el hombre piensa como hombre, es entonces porque los axolotl son capaces de hacerlo.

"Sólo una cosa era extraña: seguir pensando como antes, saber" (Cortázar 7), dice. Esto resulta tan ambiguo, que finalmente cabe preguntarse quién escribe en realidad esta historia en primera persona:

Me parece que de todo esto alcancé a comunicarle algo en los primeros días, cuando yo era todavía él. Y en esta soledad final, a la que él ya no vuelve, me consuela pensar que acaso va a escribir sobre nosotros, creyendo imaginar un cuento va a escribir todo esto sobre los axolotl. (Cortázar 8)

Es en este punto, donde el protagonista se desvincula y termina siendo un axolotl; traspasa la barrera de no comprensión al dejar de ser humano. Su visión 
es cada vez más cercana a la de anfibio, observando así con mayor distancia al hombre que fue. En palabras de Jens Andermann:

La metamorfosis en el relato moderno se compone de restos y desechos de narraciones sobrepasadas por la modernidad y que irrumpen en el texto impidiendo su continuidad y agrediendo a su lector cuya exterioridad a los sucesos es también puesta en cuestión al infringirse el orden de la letra, del logos. (9)

Ya no hay una lectura de otro, sino que hay un complemento, por medio de la metamorfosis, el texto también se transforma: "el relato de metamorfosis carga entonces con una presencia adicional, parasitaria si no fuera porque sin ella no habría relato alguno" (Andermann 12).

Un punto de encuentro importante entre Gregorio Samsa y el narrador de Axolotl resulta ser que ambos son seres solitarios que culminan mutando en una criatura igualmente ermitaña e incapaz de comunicarse por naturaleza. El insecto de por sí produce el rechazo inmediato del hombre y el axolotl, con sus rostros "como roca", en peligro de extinción, sin aparente expresión, el desconocimiento y lejanía. Por tanto, en los dos casos de metamorfosis, hay tras estos animales una rebelión ontológica del ser humano, rebelión hacia su especie y la especie animal:

El animal representa la psique no humana, lo infrahumano instintivo, así como el lado psíquico inconsciente. La primitividad del animal indica profundidad del estrato, la multiplicidad, como en todos los casos, empeora y primitiviza aún más el símbolo. La identificación con animales significa una integración del inconsciente y, a veces, como la inmersión en las aguas primordiales, un baño de renovación en las fuentes de la vida. (Cirlot 85) 
Entendiendo por psique todos los pensamientos, sentimientos y otros procesos conscientes e inconscientes, cabe destacar la unión de ambos relatos en este punto. En uno y otro se observa la alteración de este y observamos cómo, poco a poco, en el transcurso de sus respectivas historias, ambos seres están atrapados: Gregorio en forma de insecto, que finalmente fallece abandonado y olvidado, sin pena ni gloria, y el narrador de la obra de Cortázar, un hombre dentro de su imagen de piedra rosa, en esta soledad final "a la que él ya no vuelve, me consuela pensar que acaso va a escribir sobre nosotros..." (Cortázar 8).

\section{Bibliografía}

Andermann, Jens. "Tesis sobre la metamorfosis". Centro de Estudios de Teoría y Crítica Literaria 16 (2011): 1-14. eb.

Web.<http://www.celarg.org/int/arch_publi/andermann_animalidad.pdf>.

Cirlot, Juan Eduardo. Diccionario de Símbolos de tradicionales. Barcelona: Luis

Miracle, 1958. Web.<

http://www.libroesoterico.com/biblioteca/Diccionarios/Cirlot-Juan-

Eduardo-Diccionario-de-Simbolos.pdf

Cortázar, Julio. “Axolotl”. Final del fuego. 1956. n.p. n.d. Web. 6 julio 2012.

Web.<http://planlectura.educ.ar/wp-content/uploads/2016/01/Axolotl-en-

Final-de-juego-Julio-Cort\%C3\%A1zar1.pdf>.

Herrero Cecilia, Juan. "El mito como intertexto: la reescritura de los mitos en las obras literarias." Cédille. Revista de estudios franceses 2 (2006) 58-76.

Print.

Eliade, Mircea. Mitos y realidad. Barcelona: Kairós, 1999. Google Books.

Web. Mito y Realidad. Editorial Labor. 1991. 
CATEDRAL TOMADA: Revista literaria latinoamericana / Journal of Latin American Literary Criticism Catalina Villalobos Díaz

Kafka, Franz. "Metamorfosis" 1915.

Web.<http://www.edu.mec.gub.uy/biblioteca_digital/libros/k/kafka\%20$\% 201 a \% 20$ metamorfosis.pdf>

Scrimieri Martín, Rosario. "Los mitos y Jung “. Amaltea: revista de mitocrítica, ISSN-e 1989-1709, No. 0, 2008, págs. 87-112. 